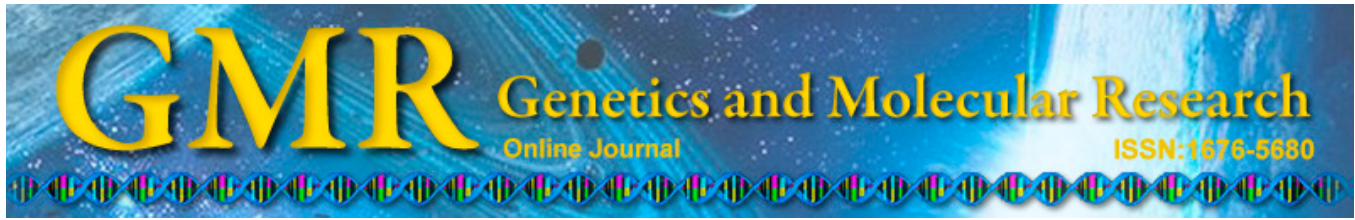

\title{
Phylogenetic analysis of widely cultivated Ganoderma in China based on the mitochondrial V4-V6 region of SSU rDNA
}

\author{
X.W. Zhou ${ }^{1,2}$, K.Q. Su ${ }^{2}$ and Y.M. Zhang ${ }^{1}$ \\ ${ }^{1}$ School of Life and Environment Science, Shanghai Normal University, \\ Shanghai, China \\ ${ }^{2}$ Key Laboratory of Urban Agriculture (South) Ministry of Agriculture, \\ Plant Biotechnology Research Center, School of Agriculture and Biology, \\ Shanghai Jiao Tong University, Shanghai, China \\ Corresponding authors: Y.M. Zhang / X.W. Zhou \\ E-mail: zhym@shnu.edu.cn / xuanweizhou@sjtu.edu.cn
}

Genet. Mol. Res. 14 (1): 886-897 (2015)

Received February 6, 2014

Accepted May 15, 2014

Published February 2, 2015

DOI http://dx.doi.org/10.4238/2015.February.2.12

\begin{abstract}
Ganoderma mushroom is one of the most prescribed traditional medicines and has been used for centuries, particularly in China, Japan, Korea, and other Asian countries. In this study, different strains of Ganoderma spp and the genetic relationships of the closely related strains were identified and investigated based on the V4-V6 region of mitochondrial small subunit ribosomal DNA of the Ganoderma species. The sizes of the mitochondrial ribosomal DNA regions from different Ganoderma species showed 2 types of sequences, 2.0 or 0.5 $\mathrm{kb}$. A phylogenetic tree was constructed, which revealed a high level of genetic diversity in Ganoderma species. Ganoderma lucidum G05 and $G$. eupense G09 strains were clustered into a $G$. resinaceum group. Ganoderma spp G29 and G22 strains were clustered into a G. lucidum group. However, Ganoderma spp G19, G20, and G21 strains were
\end{abstract}


clustered into a single group, the G. lucidum AF214475, G. sinense, G. strum G17, G. strum G36, and G. sinense G10 strains contained an intron and were clustered into other groups.

Key words: Ganoderma spp; Ganoderma identification and classification; Mitochondrial small subunit rDNA; Phylogenetic analysis.

\section{INTRODUCTION}

Ganoderma lucidum (Lingzhi or Reishi) is a bitter mushroom with remarkable health benefits (Batra et al., 2013). It has long been prescribed to prevent and treat various human diseases, particularly in China, Japan, and Korea (Boh, 2013). Various bioactive substances have been isolated and identified from G. lucidum, such as triterpenoids (Wu et al., 2013), polysaccharides (Xu et al., 2011), and fungal immunomodulatory proteins (Li et al., 2011). G. lucidum was described by Curtis based on material from England and the epithet was sanctioned by Fries (Wang et al., 2012). Within the genus of Ganoderma, more than 250 taxonomic names have been reported worldwide (Moncalvo et al., 1994), with 98 genera distributed throughout China. However, only 2 species, G. lucidum (Leyss. Ex Fr.) and G. sinense Zhao, Xu et Zhang, were described in the pharmacopoeia of China in 2005. One species, $G$. tsuage Murr, was regarded for its use in health products (Zhou et al., 2007b). Furthermore, G. lucidum, design as Lingzhi mushroom (Chinese), is also listed in the American Herbal Pharmacopoeia and Therapeutic Compendium (Sanodiya et al., 2009). Although G. lucidum has been widely considered to be a Chinese species of Ling-zhi, there are approximately 51 species with similar morphological characteristics (Li et al., 2013). Traditional identification of Ganoderma species was based on morphological features (Wu et al., 1994), physiological and developmental characteristics, and chemical components such as secondary metabolites (Hong and Jung, 2004; Xing et al., 2004). The Japanese believed that the true Ganoderma is red, but Chinese people believe that the true Ganoderma is black. Black Ganoderma has a higher medicinal value than the red mushroom (Mayzumi et al., 1997). However, the change of fruiting body color from the same genus can be greatly affected by growth conditions. As a result, the concept of species in this genus has not been well established nor universally accepted (Gottlieb et al., 2000).

DNA markers can be used to identify polymorphisms, as the genetic composition is unique for each species and is not affected by age, physiological conditions, or environmental factors (Chan, 2003). DNA can be extracted from fresh or dried tissue, powders, or mixed drug formulas (Singh et al., 1999; Warude et al., 2003); thus, this procedure is convenient, rapid, and accurate and requires only a small amount of sample. There are various well-established molecular marker techniques that have been widely used for classifying Ganoderma strains. These methods include hybridization-based methods (Luo et al., 2005), polymerase chain reaction (PCR)-based methods (Hseu et al., 1996; Luo et al., 2005; Zheng et al., 2007; Wu et al., 2009), and nuclear sequencing-based methods. These sequences contain the nucleotide sequences of a 25S-28S nuclear large subunit ribosomal DNA (rDNA) (Moncalvo et al., 1995a; Lee et al., 2006), 5.8S nuclear small subunit (SSU) rDNA (Latiffah et al., 2002), nuclear internal transcribed spacer (ITS) region rDNA (Moncalvo et al., 1995b; Gottlieb et al., 2000; Smith and Sivasithamparam, 2000; Latiffah et al., 2002), and a specific gene (Zhou et 
al., 2008) using nuclear sequencing-based methods. Although phylogenetic studies of nuclear rDNA sequences have provided insights into the relationships among Ganoderma species, the relationships between this genus and other genera of the Polyporaceae remain unclear. In contrast, nuclear ITS rDNAs are quite variable and often cannot be aligned accurately between genera and are now commonly used in the systematics of species within a genus (Moncalvo et al., 1995a; Yan et al., 1995). Therefore, the reliability and application of these methods for distinguishing medical Ganoderma from other Ganoderma species are limited.

The mitochondria of filamentous fungi have uniparental inheritance and their genomes evolve faster than the corresponding nuclear DNA, making them more suitable for differentiating closely related organisms (Ghikas et al., 2010). Mitochondrial DNA is generally considered to be appropriate for phylogenetic analyses at a family level. The small subunit ribosomal DNA (mt SSU rDNAs) were reported to evolve 16 times faster than $18 \mathrm{~S}$ rDNAs (Bruns and Szaro, 1992), but are less variable than ITS rDNAs. G. lucidum is a complex species; thus, distinguishing the subspecies is very difficult. Previous studies have shown that mt SSU rDNA sequences of Ganoderma species contained valuable phylogenetic information in conserved domains as well as in variable domains. The variable domains may be useful markers and were helpful for describing phylogenetic groups (Hong et al., 2002; Hong and Jung, 2004).

In this study, we sequenced V4-V6 mt SSU rDNA sequences, which was used to conduct a genetic study of 10 widely cultivated Ganoderma strains. The aim of this study was to lay a foundation for establishing a genetic database, which may provide molecular evidence for the selection and breeding of eminent cultivars and to determine genetic relationship in Ganoderma.

\section{MATERIAL AND METHODS}

\section{Ganoderma materials}

Experienced botanists collected plant specimens, including commercial cultivars and wild varieties that represented the great diversification of types from different regions of China as follows: G. lucidum GIM 5.251 (G05) from the Microbiological Culture Collection Center of Guangdong Institute of Microbiology; G. eupense 51229 (G09) and G. sinensis 51332 (G10) from the Agricultural Culture Collection of China (ACCC); black Ganoderma spp (G17) and white Ganoderma spp (G19) from the Institute of Edible Fungi of Middle China (Wuhan); Ganoderma spp (G20) and G. atrum (G36) from the Institute of Edible Fungi, Shanghai Academy of Agricultural Sciences; Ganoderma spp (G22) from the Sichuan Academy of Agricultural Sciences; Ganoderma spp (G21) from Shaanxi University of Technology, Ganoderma spp (G29) from Shandong Agriculture University. Ganoderma mycelia were prepared in liquid culture in our laboratory.

\section{Ganoderma cultures}

Stock cultures were maintained in slant tubes at $4^{\circ} \mathrm{C}$ on improved potato dextrose agar medium, containing $200 \mathrm{~g} / \mathrm{L}$ potato, $20 \mathrm{~g} / \mathrm{L}$ dextrose, $1.5 \mathrm{~g} / \mathrm{L} \mathrm{MgSO}_{4} \cdot 7 \mathrm{H}_{2} \mathrm{O}, 2.5 \mathrm{~g} / \mathrm{L} \mathrm{KH}_{2} \mathrm{PO}_{4}$, $10 \mathrm{mg} / \mathrm{L}$ vitamin $\mathrm{B}_{1}$, and $20 \mathrm{~g} / \mathrm{L}$ agar. Stock cultures were transferred to Petri dishes containing potato dextrose agar and allowed to incubate for 5 days at $28^{\circ} \mathrm{C}$. Two agar blocks $(\varphi 9 \mathrm{~mm})$ 
were obtained and inoculated into a $250-\mathrm{mL}$ Erlenmeyer flask containing $50 \mathrm{~mL}$ pre-culture liquid medium, composed of $35 \mathrm{~g} / \mathrm{L}$ sucrose, $5 \mathrm{~g} / \mathrm{L}$ peptone, $2.5 \mathrm{~g} / \mathrm{L}$ yeast extract, $0.5 \mathrm{~g} / \mathrm{L}$ $\mathrm{MgSO}_{4}, 1 \mathrm{~g} / \mathrm{L} \mathrm{KH}_{2} \mathrm{PO}_{4}$, and $50 \mathrm{mg} / \mathrm{L}$ vitamin $\mathrm{B}_{1}$ at an initial $\mathrm{pH}$ of 6.8 . The mycelia were maintained on a rotary shaker at $120 \mathrm{rpm}$ and $28^{\circ} \mathrm{C}$ for $5-10$ days and harvested by centrifugation at $5000 \mathrm{~g}$ for $15 \mathrm{~min}$. After washing 3 times with phosphate-buffered saline, the mycelia were collected by centrifugation and then treated with dry refrigeration to extract genomic DNA.

\section{DNA extraction}

DNA extractions were performed using the high-salt and low-pH method (Zhou et al., 2007a). First $1 \mathrm{~g}$ material was homogenized in liquid nitrogen in a pre-cooled mortar, transferred to a $50-\mathrm{mL}$ tube containing $5.0 \mathrm{~mL}$ pre-warmed $\left(65^{\circ} \mathrm{C}\right)$ extraction buffer $(1.4 \% \mathrm{SDS}$, $100 \mathrm{mM}$ NaAc, pH 4.8, $50 \mathrm{mM}$ EDTA, pH 8.0, $500 \mathrm{mM} \mathrm{NaCl}, \mathrm{pH} 4.8$ ) and mixed gently. The mixture was then placed in a $65^{\circ} \mathrm{C}$ water bath for $30 \mathrm{~min}$. The homogenate was pelleted by centrifugation at $10,000 \mathrm{~g}$ for $10 \mathrm{~min}$ and the aqueous phase was removed to a new tube containing $2 / 3$ vol. $2.5 \mathrm{M} \mathrm{KAc}, \mathrm{pH} 4.8$, solution. After the tube was shaken gently, the sample was incubated for $30 \mathrm{~min}$ at $0^{\circ} \mathrm{C}$ until the protein was precipitated. The protein was pelleted by centrifugation at $10,000 \mathrm{~g}$ for $10 \mathrm{~min}$ at $4^{\circ} \mathrm{C}$ and the aqueous phase was removed to a new tube containing $2 / 3 \mathrm{vol}$. cold isopropanol; the sample was incubated for at least $16 \mathrm{~h}$ at $-20^{\circ} \mathrm{C}$. After centrifugation, the pellet was washed with $70 \%$ ethanol, dried, and resuspended in 500 $\mu \mathrm{L}$ TE buffer. The DNA was stored at $-20^{\circ} \mathrm{C}$.

\section{PCR amplification}

Two primers, BMS65 and BMS113, were designed based on the highly conserved V4V6 sequence of SSU rDNA of Ganoderma. The following PCR conditions were used: $10 \mathrm{~min}$ at $95^{\circ} \mathrm{C}, 35$ cycles $\left(30 \mathrm{~s}\right.$ at $95^{\circ} \mathrm{C}, 30 \mathrm{~s}$ at $60^{\circ} \mathrm{C}, 2 \mathrm{~min}$ at $\left.72^{\circ} \mathrm{C}\right)$, and $10 \mathrm{~min}$ at $72^{\circ} \mathrm{C}$.

\section{Cloning and sequencing}

PCR products were purified using the Gel Extraction Mini Kit (Watson Biotechnologies Inc., Taipei, Taiwan), ligated into pMD18-T vectors (Takara, Shiga, Japan), transformed into Escherichia coli strain DH5 $\alpha$, and then sequenced (Shanghai Sangon Biological Engineering Technology and Service Co. Ltd., Shanghai, China).

\section{Sequence alignment and analysis}

Sequence data were compared to other isolates used and are listed in Table 1. DNA sequences were aligned using the ClustalW program in the biology workbench version 3.2 (Thompson et al., 1994). Final alignments were visually examined and adjusted manually. Phylogenetic analysis was conducted using the MEGA version 2.1 program (Tamura et al., 2011). 
X.W. Zhou et al.

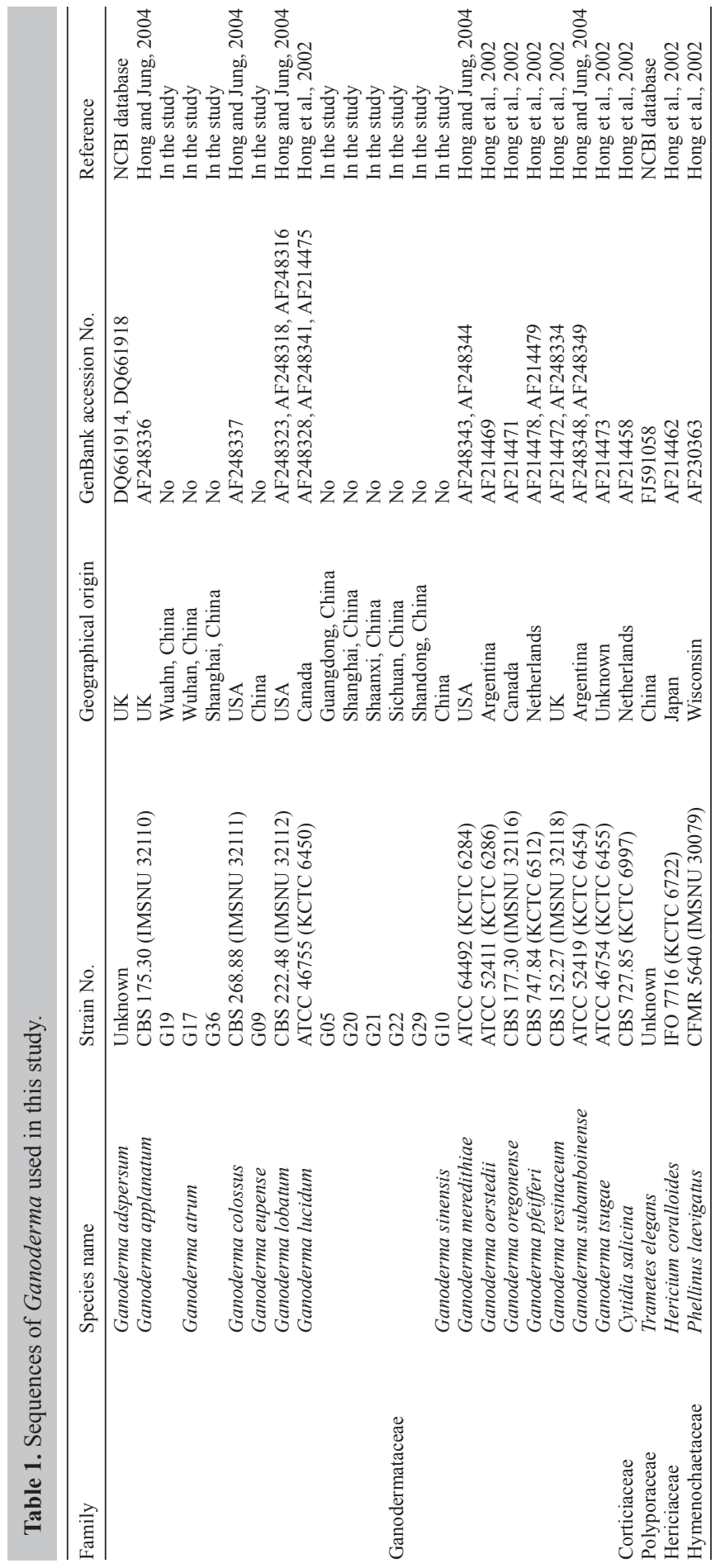




\section{RESULTS}

\section{Sequence analysis of mt SSU rDNA}

The full-length sequence of mt SSU rDNA from G. lucidum (AF214475) and G. sinense (KF673550) was 3506 bp (Li et al., 2013) and contained 1 intron. The sequence of the intron was 1506 bp (1041-2547). However, the full-length mt SSU rDNA sequence from the other Ganoderma species was approximately 2000 bp, contained no intron, including $G$. applanatum, G. lobatum, and G. meredithiae (Hong et al., 2002). The analysis of the fulllength sequence revealed that there are 9 variable domains (V1-V9), with an additional intron located between positions V4-V5 (Figure 1).

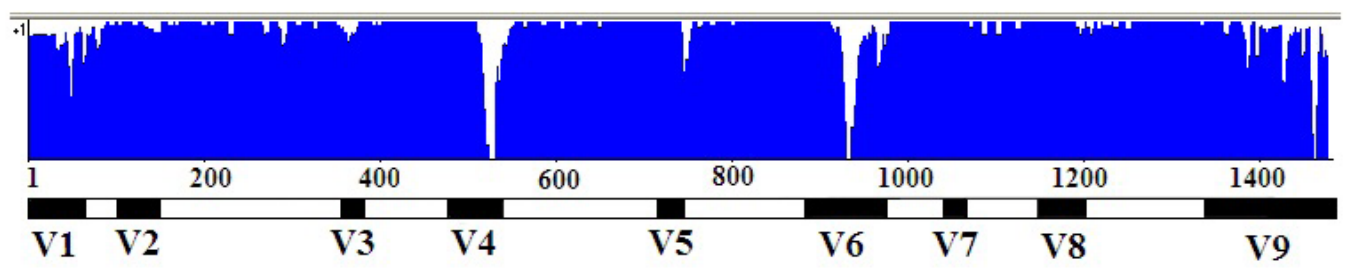

Figure 1. Alignment of 9 variable domains (V1-V9) shown using Vector NTI.

\section{Characteristics of Ganoderma mt SSU rDNA}

A previous study showed that among the 9 variable domains, V1, V4, V5, V6, and V9 were more variable than the other 4 variable domains (V2, V3, V7, and V8), using $37 \mathrm{mt} \mathrm{SSU}$ sequences of Ganoderma (Hong and Jung, 2004). Twelve mt SSU sequences of Ganoderma were aligned unambiguously, except for V4, V5, and V6 variable domains (Figure 1) that had undergone several insertion/deletion events. The $12 \mathrm{mt} \mathrm{SSU}$ full-length sequences of Ganoderma represented different species, including G. adspersum, G. applanatum, G. colossus, $G$. lobatum, G. lucidum, G. meredithiae, G. oerstedii, G. oregonense, G. pfeifferi, G. resinaceum, G. subamboinense, and G. tsugae. Phylogenetic relationships among the 12 Ganoderma species were inferred by heuristic search options and compared with the results of the neighborjoining tree reconstructed by Kimura's two-parameter model. Based on monophyly, branch length, and bootstrap support, Ganoderma species were divided into 6 monophyletic groups: I. G. colossus group, II. G. applanatum group, III. G. tsugae group, IV. Asian G. lucidum group, V. G. meredithiae group, and VI. G. resinaceum (Figure 2A). The results are consistent with the results of a previous study (Hong and Jung, 2004). Amplification of full-length sequences of $\mathrm{mt} \mathrm{SSU}$ sequences is very difficult using PCR, particularly when the gene contains a large intron. Thus, we selected the V4-V6 region of mt SSU rDNA sequences to evaluate the relationships between species. The results were in agreement with full-length sequences (Figure 2B). Thus, the V4-V6 region of mt SSU rDNA sequences can be used as molecular markers for resolving phylogenetic relationships between Ganoderma species. 

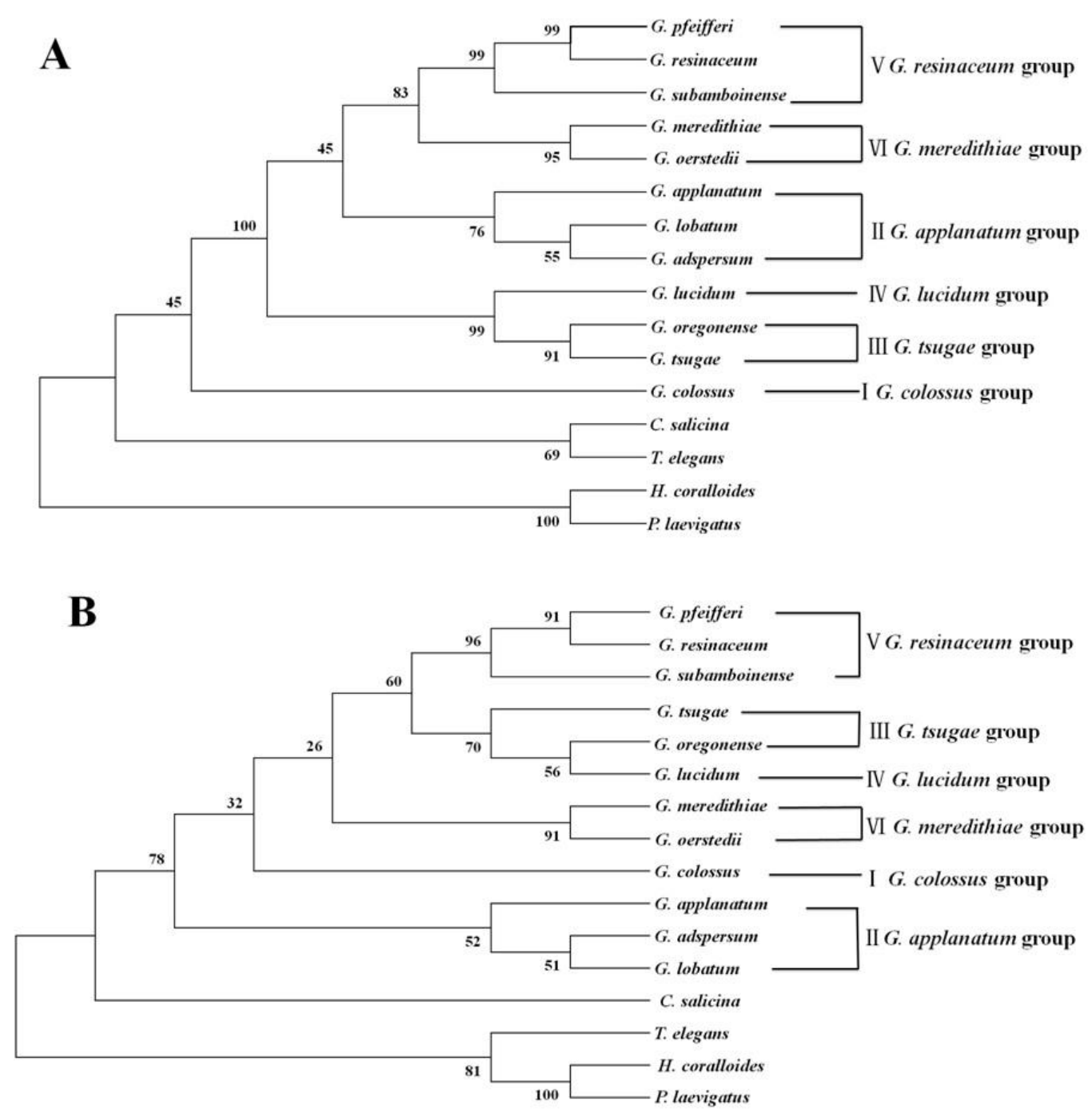

Figure 2. Phylogenetic trees constructed from unambiguously aligned full-length (A) or V4-V6 region sequence (B) of mt SSU rDNA from Ganoderma species as determined by NJ analysis.

\section{Sequence amplification of mt SSU rDNA}

The DNA isolated from the mycelia of Ganoderma and the primers BMS65 (5'-CTGG TGCCAGAAGACTCGGTAA-3') (512-533) and BMS113 (5'-GACAGCCATGCAACACCT GTA-3') (1043-1063) were used to specifically amplify the V4, V5, and V6 region sequences by PCR. The amplified $\mathrm{mt}$ SSU fragments of 7 strains using the primers BMS65 and BMS113 were approximately $550 \mathrm{bp}$ in length for all taxa except G. sinensis (G10), G. atrum (G17), and G. atrum (G36), for which it was approximately $2 \mathrm{~kb}$ in length, as visualized on agarose gels stained with ethidium bromide (Figure 3). The 7 strains of PCR products producing bands 
of $550 \mathrm{bp}$ included G. lucidum (G5), G. eupense (G9), G. applanatum (G19), and Ganoderma $\operatorname{spp}(\mathrm{G} 20, \mathrm{G} 21, \mathrm{G} 22, \mathrm{G} 29)$. Based on nucleotide sequence alignment, the differences in length of the PCR products of G. sinensis (G10), G. atrum (G17), and G. atrum (G36) resulted from a single insert located approximately 1506 bp between positions V4-V5 (Figure 4).

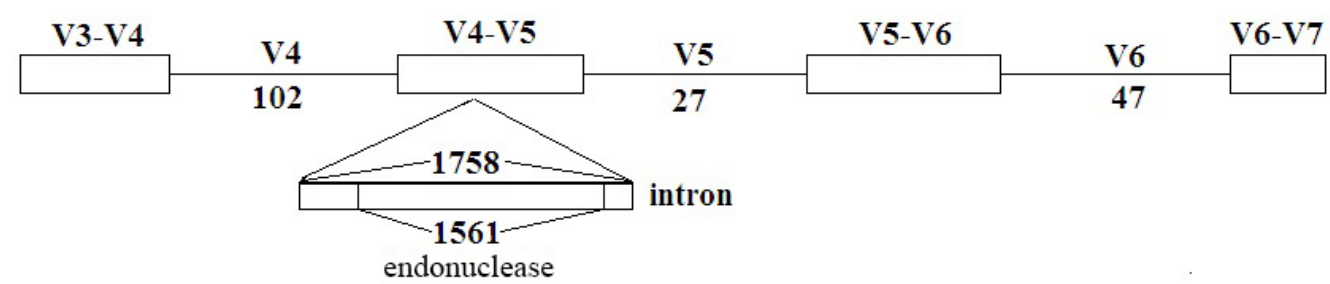

Figure 3. Locations of 3 variable domains (V4-V6) are shown as boxes in the diagram of the mt SSU rDNA gene of Ganoderma atrum $\mathrm{G} 36$. The position of the group II intron found in 3 strains was indicated between V4 and V5 domains.
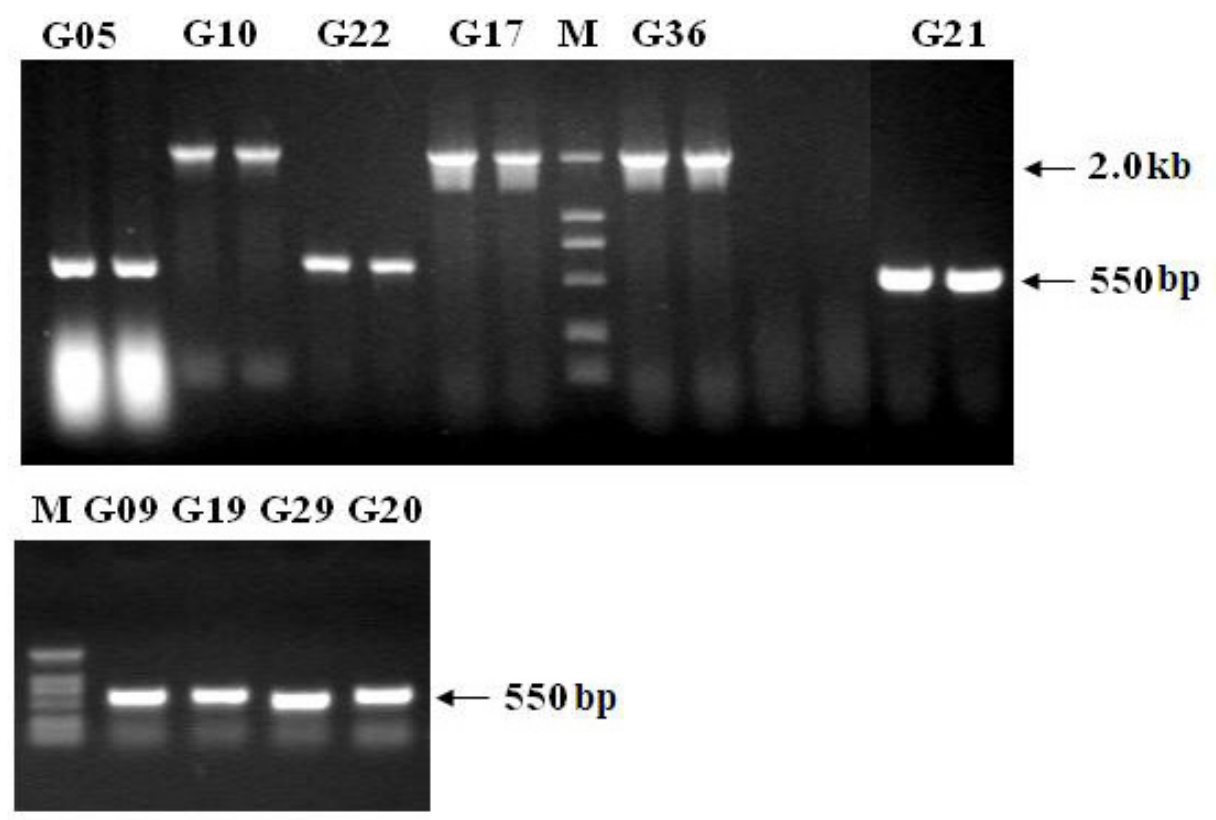

Figure 4. PCR of the mt SSU rDNA from the Ganoderma isolates. Lane $M=$ molecular marker.

\section{Sequence alignment}

Sequence alignment of the 7 taxa was carried out. Alignments of the V4-V6 regions are included in Figure S1. The nucleotide sequence in the V4 region varied from 214-283 bp, with $77.4 \%$ consensus and $59.7 \%$ identity among the 7 taxa. The nucleotide sequence in the V5 region varied from $189-194 \mathrm{bp}$, with $95.1 \%$ consensus and $74.4 \%$ identity among the 7 taxa. The nucleotide sequence in the V6 region varied from $117-144 \mathrm{bp}$, with $93.9 \%$ consensus and $63.32 \%$ identity among the 7 taxa. The frequency of variable sites was different in the 3 regions, but was primarily located in the $\mathrm{V} 4$ region. 


\section{Phylogenetic analysis}

To determine the evolutionary relationships of the 10 species between each other and with other Ganoderma species at the molecular level, and to identify the species, phylogenetic analysis was performed. Sequence data from the V4-V6 regions were aligned against the published sequence data, which is available from the GenBank database at the National Center for Biotechnology Information. Aligned sequences were then analyzed for evolutionary relationships using the ClustalW program (version 3.1). Sequences were also subjected to pairwise distance analysis in MEGA (Figure 5). The resulting phylogenetic tree suggested a wide range of genetic diversity among Ganoderma species. Interestingly, G. lucidum G05 and G. eupense G11 strains clustered into the G. resinaceum group. Ganoderma spp G22 and G29 strains clustered into the G. lucidum group. However, Ganoderma spp G19, G20, and G21 strains clustered into a single group, while the G. lucidum AF214475, G. sinense, G. strum G10, G. strum G36, and G. sinense G17 strains were clustered into other groups. The G. lucidum AF214475, G. sinense, G. strum G10, G. strum G36, and G. sinense G17 contain an intron.

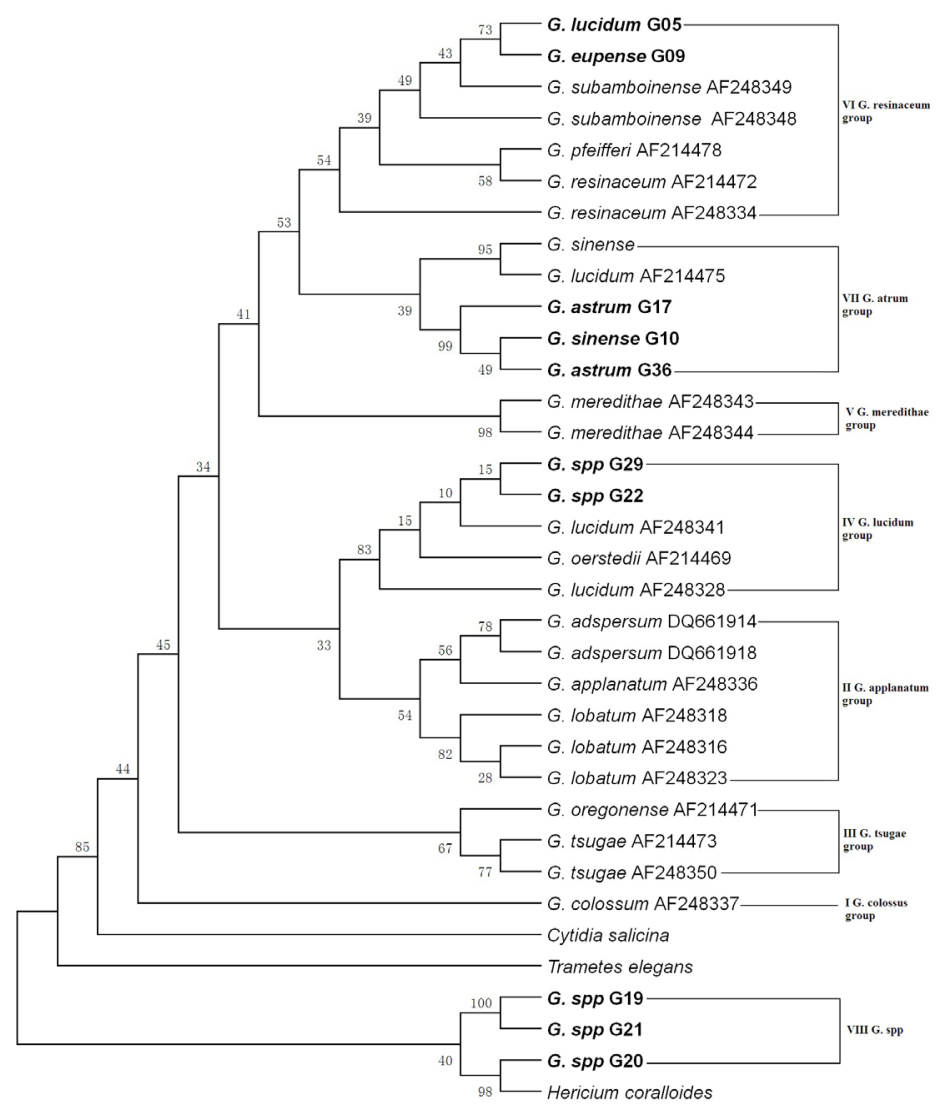

Figure 5. Phylogenetic tree indicating the relationship among isolates of Ganoderma based on the V4-V6 region sequence of $\mathrm{mt}$ SSU rDNA. The mt SSU rDNA sequences obtained from GenBank are shown with accession numbers. 


\section{DISCUSSION}

Ganoderma lucidum (Ling-zhi), a widely cultivated fungus in China, has a long history of use in traditional Chinese medicine. The first record of Ganoderma in China was by Teng in 1934, who described 4 species and 1 variety. One of the species recorded was referred to as G. lucidum (Wang et al., 2012). A total of 98 species distributed throughout China were assembled by Zhao and Zhang in 'Flora Fungorum Sinicorum 18: Ganodermataceae', including 58 new species based on collections from China (Zhao and Zhang, 2000). Ling Zhi was divided into 6 types based on their different colors, such as Qing Zhi (cyan), Chi Zhi (red, G. lucidum), Huang Zhi (yellow), Bai Zhi (white), Hei Zhi (black), and Zi Zhi (purple, G. sinensis) in the ancient Chinese medical encyclopedias (Lin, 2011). Ganodermataceae contains 4 genera, including Ganoderma, Amaurodama, Haddowia, and Humphreya. Ganoderma consists of the subgenus Ganoderma, which includes Sect. Ganoderma and Sect. Phaenema, subgenus Eflvingia, and subgenus Trachyderma (Zhao and Zhang, 2000). Various collections from several provinces have been collected, including Anhui, Fujian, Guangxi, Guizhou, Hainan, Jiangsu, Sichuan, Yunnan, and Zhejiang. The name was then adapted by contemporary Chinese mycologists and used to refer to Ganoderma species widely cultivated in China after the 1970s (Wu and Dai, 2005). Cultivation of the species became popular in the 1980s and 1990s and the name G. lucidum appeared in many publications and commercial catalogs, and use of this name has increased since then. In fact, G. lucidum is not only incorrectly recorded in China, but has also been reported incorrectly worldwide. A variety of molecular marking methods have been used to identify cultivars of Ganoderma, such as random amplified polymorphic DNA (Zhao et al., 2003; Luo et al., 2005), internal transcribed sequences, restriction fragment length polymorphism analysis of PCR-amplified fragments (Luo et al., 2005; Su et al., 2007; Zhou et al., 2008), amplified fragment length polymorphism (Wu et al., 2009). PCR-restriction fragment length polymorphism shows good stability and high repeatability, which is important for phylogenetic analysis. Its resolution is high in genera and in a genus, but intraspecific polymorphism identification is not specific. Research also shows that this technique shows good resolution in different strains, but it cannot reveal differences between strains. Because a large quantity of samples can be analyzed with high sensitivity, random amplified polymorphic DNA uses the whole genome as a target and is suitable for identifying different species. However, this method shows low stability. Based on differences in fingerprints between strains, amplified fragment length polymorphism can effectively distinguish the genotypes of different strains, which may be effective for quality control when analyzing and identifying cultivated strains. Amplified fragment length polymorphism has been successfully used to identify the main cultivated species of Ganoderma strains, and 30 Ganoderma production strains from various districts of China formed a tight cluster in 8 groups (Wu et al., 2009).

In the study, 2 strains were chosen from the Agricultural Culture Collection of China as controls in order to identify 8 other strains for their taxonomic positions and medical values. The 2 controls were clustered into 2 groups, G. resinaceum and G. atrum. Compared with the traditional taxonomical system, these clustering results are in agreement with the taxonomical system. Two strains, G29 from Shandong Agriculture University and G22 from the Sichuan Academy of Agricultural Sciences, were clustered to group G. lucidum. The results indicated that the 2 strains had the same features and medical values. Strains G12 collected from the Agricultural Culture Collection of China, G20 collected from the Institute of Edible Fungi of Middle China, and G36 collected from the Institute of Edible Fungi, Shanghai Academy of 
Agricultural Sciences were clustered to G. atrum, although they were collected from different sites. Sequences for the 3 strains and 2 strains were obtained from the NCBI database and contained an intron. Strain G19, which was collected from the Institute of Edible Fungi of Middle China (Wuhan), G20 collected from the Institute of Edible Fungi, Shanghai Academy of Agricultural Sciences, and G21 collected from the Shaanxi University of Technology were clustered into a group. Although they belonged to Ganoderma, the strain G19 belong to Sect. Phaeonema, while strain G20 has a closer genetic relationship with Sect. Phaeonema using amplified fragment length polymorphism (Wu et al., 2009). Strain 21 was originally from South Korea, and although it belongs to Sect. Ganoderma, some variation developed after it was introduced to the area (Wu et al., 2009). The morphological characteristics and medical value of the 3 strains require further analysis.

\section{ACKNOWLEDGMENTS}

Research supported by grants from the National Natural Science Foundation of China (\#30771500), the Shanghai Science and Technology Committee and the Shanghai Leading Academic Discipline Project.

\section{Supplementary material}

\section{REFERENCES}

Batra P, Sharma AK and Khajuria R (2013). Probing Lingzhi or Reishi medicinal mushroom Ganoderma lucidum (higher Basidiomycetes): a bitter mushroom with amazing health benefits. Int. J. Med. Mushrooms 15: 127-143.

Boh B (2013). Ganoderma lucidum: a potential for biotechnological production of anti-cancer and immunomodulatory drugs. Recent Pat. Anticancer Drug Discov. 8: 255-287.

Bruns TD and Szaro TM (1992). Rate and mode differences between nuclear and mitochondrial small-subunit rRNA genes in mushrooms. Mol. Biol. Evol. 9: 836-855.

Chan K (2003). Some aspects of toxic contaminants in herbal medicine. Chemosphere 52: 1361-1371.

Ghikas DV, Kouvelis VN and Typas MA (2010). Phylogenetic and biogeographic implications inferred by mitochondrial intergenic region analyses and ITS1-5.8S-ITS2 of the entomopathogenic fungi Beauveria bassiana and $B$. brongniartii. BMC Microbiol. 10: 174.

Gottlieb AM, Ferrer E and Wright JE (2000). rDNA analyses as an aid to the taxonomy of species of Ganoderma. Mycol. Res. 104: 1033-1045.

Hong SG and Jung HS (2004). Phylogenetic analysis of Ganoderma based on nearly complete mitochondrial small-subunit ribosomal DNA sequences. Mycologia 96: 742-755.

Hong SG, Jeong W and Jung HS (2002). Amplification of mitochondrial small subunit ribosomal DNA of polypores and its potential for phylogenetic analysis. Mycologia 94: 823-833.

Hseu RS, Wang HH, Wang HF and Moncalvo JM (1996). Differentiation and grouping of isolates of the Ganoderma lucidum complex by random amplified polymorphic DNA-PCR compared with grouping on the basis of internal transcribed spacer sequences. Appl. Environ. Microbiol. 62: 1354-1363.

Latiffah Z, Harikrishna K, Tan SG, Tan SH, et al. (2002). Restriction analysis and sequencing of the ITS regions and 5.8S gene of rDNA of Ganoderma isolates from infected oil palm and coconut stumps in Malaysia. Ann. Appl. Biol. 141: 133-142.

Lee JS, Lim MO, Cho KY, Cho JH, et al. (2006). Identification of medicinal mushroom species based on nuclear large subunit rDNA sequences. J. Microbiol. 41: 29-34.

Li J, Zhang J, Chen H, Chen X, et al. (2013). Complete mitochondrial genome of the medicinal mushroom Ganoderma lucidum. PLoS One 8: e72038.

Li QZ, Wang XF and Zhou XW (2011). Recent status and prospects of the fungal immunomodulatory protein family. Crit. Rev. Biotechnol. 31: 365-375.

Lin ZB (2011). Modern Study of Ganoderma lucidum (II). Beijing Medical University Press, Beijing. 
Luo LZ, Lin SQ, Xie BG and Lin ZB (2005). DNA fingerprinting analysis of Ganoderma strains. Acta Edulis Fungi 12: 7-13.

Mayzumi F, Okamoto H and Mizuno T (1997). IV. Cultivation of Reishi (Ganoderma lucidum). Cultivation of reddish Reishi (Ganoderma lucidum, Red). Food Rev. Int. 13: 365-382.

Moncalvo JM, Wang HF, Wang HH and Hseu RS (1994). Molecular studies in the Ganoderma lucidum complex. In 94' Int. Symp. Ganoderma Res. (Lin ZB, ed.). Beijing Medical University Press, Beijing, 12-13.

Moncalvo JM, Wang HF and Hseu RS (1995a). Gene phylogeny of the Ganoderma lucidum complex based on ribosomal DNA sequences. Comparison with traditional taxonomic characters. Mycol. Res. 99: 1489-1499.

Moncalvo JM, Wang HH and Hseu RS (1995b). Phylogenetic relationships in Ganoderma inferred from the internal transcribed spacers and 25S ribosomal DNA sequences. Mycologia 87: 223-238.

Sanodiya BS, Thakur GS, Baghel RK, Prasad GB, et al. (2009). Ganoderma lucidum: a potent pharmacological macrofungus. Curr. Pharm. Biotechnol. 10: 717-742.

Singh M, Bandana and Ahuja PS (1999). Isolation and PCR amplification of genomic DNA from market samples of dry tea. Plant Mol. Biol. Rep. 17: 171-178.

Smith BJ and Sivasithamparam K (2000). Internal transcribed spacer ribosomal DNA sequence of five species of Ganoderma from Australia. Mycol. Res. 104: 943-951.

Su CL, Tang CH, Zhang JS, Chen MJ, et al. (2007). The phylogenetic relationship of cultivated isolates of Ganoderma in China inferred from nuclear ribosomal DNA ITS sequences. Wei Sheng Wu Xue Bao 47: 11-16.

Tamura K, Peterson D, Peterson N, Stecher G, et al. (2011). MEGA5: molecular evolutionary genetics analysis using maximum likelihood, evolutionary distance, and maximum parsimony methods. Mol. Biol. Evol. 28: 2731-2739.

Thompson JD, Higgins DG and Gibson TJ (1994). CLUSTAL W: improving the sensitivity of progressive multiple sequence alignment through sequence weighting, position-specific gap penalties and weight matrix choice. Nucleic Acid Res. 22: 4673-4680.

Wang XC, Xi RJ, Li Y, Wang DM, et al. (2012). The species identity of the widely cultivated Ganoderma, 'G. lucidum' (Ling-zhi), in China. PLoS One 7: e40857.

Warude D, Chavan P, Joshi K and Patwardhan B (2003). DNA isolation from fresh and dry plant samples with highly acidic tissue extracts. Plant Mol. Biol. Rep. 21: 467.

Wu GS, Guo JJ, Bao JL, Li XW, et al. (2013). Anti-cancer properties of triterpenoids isolated from Ganoderma lucidum - a review. Expert Opin. Investig. Drugs 22: 981-992.

Wu SQ, Guo XB, Zhou X, Li XS, et al. (2009). AFLP analysis of genetic diversity in main cultivated strains of Ganoderma spp Afr. J. Biotechnol. 8: 3448-3454.

Wu XL and Dai YC (2005). Coloured illustrations of Ganodermataceae of China. Science Press, Beijing.

Wu XL, Zhang XQ, Zhong JX, Zhou FL, et al. (1994). Study on the Ganodermataceae species from Guizhou with descriptions of a new species. Guizhou Sci. 12: 54-63.

Xing Z, Yu Q, Zhang J and Pan Y (2004). Comparative study on triterpenes in different Ganoderma species. J. Chin. Med. Mat. 27: 575-576.

Xu Z, Chen X, Zhong Z, Chen L, et al. (2011). Ganoderma lucidum polysaccharides: immunomodulation and potential anti-tumor activities. Am. J. Chin. Med. 39: 15-27.

Yan ZH, Rogers SO and Wang CJK (1995). Assessment of Phialophora species based on ribosomal DNA internal transcribed spacers and morphology. Mycologia 87: 72-83.

Zhao JD and Zhang XQ (2000). Flora Fungorum Sinicorum 18: Ganodermataceae. Science Press, Beijing.

Zhao MW, Chen MJ, Wang N, Liang WQ, et al. (2003). Study on genetic relationship among some commercial strains of Ganoderma. J. Nanjing Agric. Univ. 26: 60-63.

Zheng LY, Jia DH, Luo X and Yang ZR (2007). AFLP analysis for genetic diversity of Ganoderma. Chin. J. Chin. Mater. Med. 32: 1733-1736.

Zhou XW, Li QZ, Zhao JY, Tang KX, et al. (2007a). Comparison of rapid DNA extraction methods applied to PCR identification of medicinal mushroom Ganoderma spp Prep. Biochem. Biotechnol. 37: 369-380.

Zhou XW, Lin J, Yin YZ, Zhao JY, et al. (2007b). Ganodermataceae: natural products and their related pharmacological functions. Am. J. Chinese Med. 35: 559-574.

Zhou XW, Li QZ, Yin YZ, Chen YY, et al. (2008). Identification of medicinal Ganoderma species based on PCR with specific primers and PCR-RFLP. Planta Med. 74: 197-200. 